\title{
HEPARAN SULFATE: LANDING SITE FOR THE DENGUE VIRAL STRAINS TO GAIN ENTRY TO THE HOST CELLS
}

\author{
ABDUL GHAYUM PAPULZAI ${ }^{1}$, NIKHIYA MANUEL JOHN ${ }^{1}$, SUDHAKAR MALLA $^{2 *}$
}

${ }^{1}$ Department of Biotechnology, St. George College of Management and Science, Bengaluru, Karnataka, India. ${ }^{2}$ Department of Biotechnology, Indian Academy Degree College-Autonomous, Bengaluru, Karnataka, India. Email: sudhasanmoon2000@gmail.com

Received: 25 June 2021, Revised and Accepted: 30 September 2021

\begin{abstract}
Humans usually contract dengue by being bitten by arthropods, and more than 3.6 billion people are at risk per year. Although studies are conducted to screen and trace out the possible pathophysiology of the virus, an adequate receptor-based study has not been completed. Understanding how the dengue virus (DV) engraves its landing sites requires identification of such cellular receptors. In many model studies, heparan sulfate (HS) has been reported to act as a DV receptor under various conditions. However, the physiological relevance of these findings remains uncertain. Therefore, it is still unclear whether HS is used by viral strains or not, and if at all used by clinical or non-cell culture-adapted strains of DV. The present review aims to identify relevant experimental evidences that confirm the possible interaction between envelope protein and HS chains. We collected data from a series of studies to conclude the interactive role.
\end{abstract}

Keywords: DENV, Envelope protein, Heparan sulfate, Conserved domains.

(C) 2021 The Authors. Published by Innovare Academic Sciences Pvt Ltd. This is an open access article under the CC BY license (http://creativecommons.org/ licenses/by/4.0/) DOI: http://dx.doi.org/10.22159/ajpcr.2021v14i11.42536. Journal homepage: https://innovareacademics.in/journals/index.php/ajpcr

\section{INTRODUCTION}

Dengue viruses (DV) are members of the flavivirus family primarily transmitted to humans by the Aedes aegypti mosquito [1]. Four dengue virus serotypes are predominantly infective by any of these predisposes individuals to more severe disease following a subsequent infection by a different dengue serotype [2,3]. Although strategies to combat dengue virus pathogenesis have been developed, it is widely acknowledged that pre-existing, non-neutralizing antibodies to dengue viruses enhance infection of immune cells and increase the risk of DHF and DSS following dengue virus infection [2].

Statistical analysis reveals an estimate of 50 million people being exposed to infection by dengue virus annually and approximately 500,000$1,000,000$ infections culminate in dengue hemorrhagic fever (DHF) or dengue shock syndrome (DSS), with 5-30\% mortality rates [4,5].

Dengue virus is an enveloped virus measuring almost $50 \mathrm{~nm}$ in diameter. On the viral membrane, the envelope glycoprotein (E protein) is present (Fig. 1). The E protein binds to receptors on host membranes and also acts as an antigen against host immune response that induces neutralizing antibodies to be produced [6]. Proteins are divided into domains I, II, and III, referred to as domains I, II, and III, respectively. The hinge region is linked to both of the other functional domains. As a result of fluctuations in external $\mathrm{pH}$, the $\mathrm{E}$ protein structure changes due to the mobility of this region. A hydrophobic-rich peptide sequence [7] features membrane fusion activity and contributes to dimerization of E proteins in domain II [8].

Domain III is thought to be involved in the binding to receptor molecules present on the host cell membrane (Fig. 1). During viral infection, the adsorption of viral particles is initiated by binding of $\mathrm{E}$ protein to receptor molecules present on the host cell membrane. Endocytosis is then used to take the viruses into the cell. Through the action of an $\mathrm{E}$ protein fusion peptide inside endosomes, the $\mathrm{pH}$ decreases inside endosomes formed by the fusion of lysosomes. Eventually, the nucleocapsid enters the cytoplasm, and the virus genome is released into the cytoplasm.

Mosquitoes transmit the dengue virus from human to human making the virus more efficient to infect and proliferate in both humans and mosquitoes as hosts [9]. Several studies have been performed to determine the host receptor(s) for dengue virus in the past 30 years. Several molecules as such are proposed as possible receptors in human and mosquito cells and tissues [10,11].

This process is mediated by envelop proteins (E), which actively bind to the dengue virus' receptor. Cell surfaces of mammals contain Heparan sulfate, nLc4Cer, DCSIG, L-SIG, and mannose receptors which bind to DEN 1-4 serotypes (Fig. 2). DEN-2 serotype also binds with HSP70/ HSP90, GRP78, and CD14- associated protein. Both the DEN 1-3 serotypes bind to Laminin receptor bind $[12,13]$.

Among the potential candidates are sulfated glycosaminoglycans (GAGs), lectins, glycosphingolipids (GSLs), laminin-binding proteins, GSLs, chaperones, and unknown proteins [14]. Diverse studies strongly suggest that human dengue virus infection in the absence of heparan sulfate and DC-SIGN may result in death. It is thought that heparan sulfate functions as a co-receptor, which associates with other molecules to form functional complexes and facilitates virus infection [15]. By means of DC-SIGN, which is specifically expressed on the cells, DENV infects the dendritic cells.

It acts as the main receptor for viruses in the blood after these cells move to where they are propagated and disseminated by the peripheral lymph nodes [16]. Several studies supported the suggestion that carbohydrate molecules in extracellular matrix are strongly related to DENV receptors [17].

It is the lack of involvement of GAGs in viral infection of mosquito cells that makes it different from mammalian cells. To date, laminin-binding proteins, GSLs, and other undefined proteins have been proposed in mosquito cells and organs [18]. It appears that the interaction between the virus and host cell in mosquitoes is mediated by molecules that differ from those found in mammals.

\section{VIRUS ENTRY TO HOST CELLS}

Aedes mosquitoes transmit the dengue virus, which is an arthropodborne disease. Humans and nonhuman primates are both susceptible to dengue fever and hemorrhagic diseases caused by the virus. 


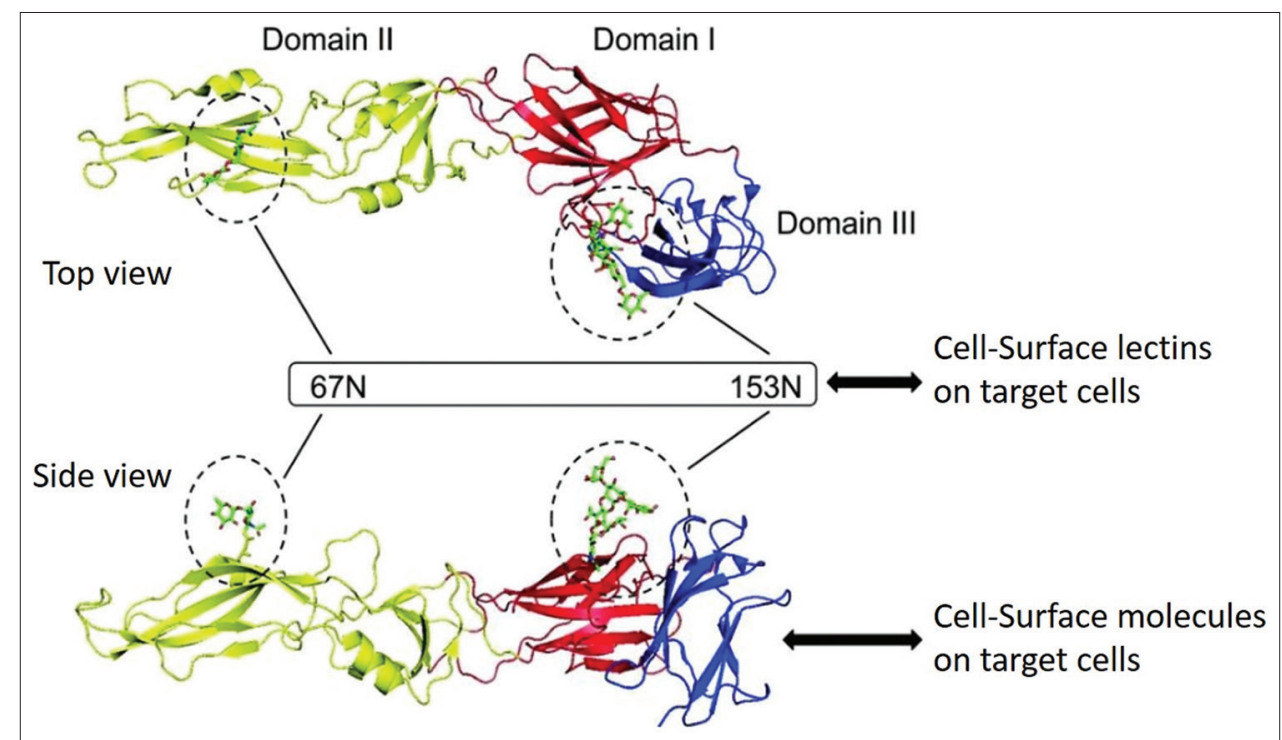

Fig. 1: Diagram showing the protein interaction of DENV with lectin and other molecules expressed on the host cell surface. Diagram retrieved from Sobia Idrees, 2012 [8]

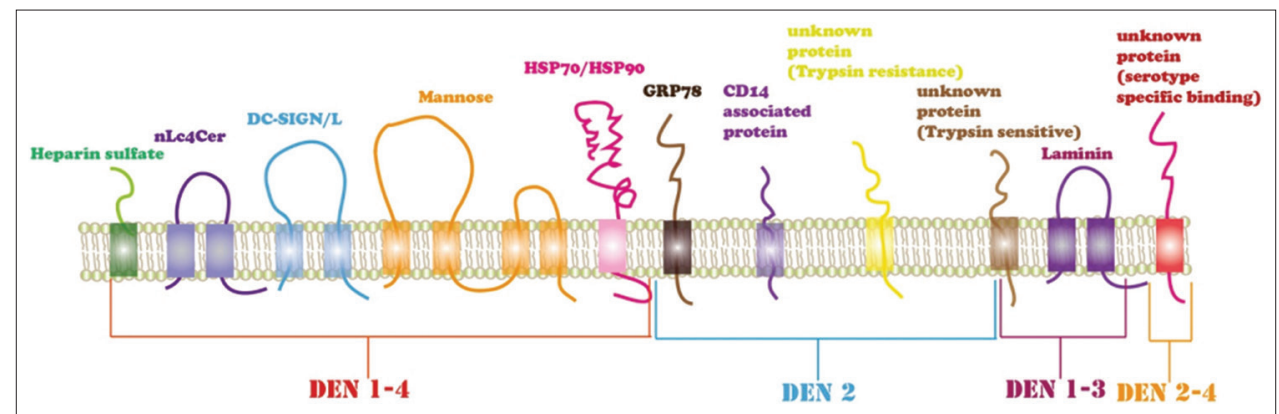

Fig. 2: Image showing the possible receptors for landing of the DENV on the host cell lines. Image retrieved from Sobia Idrees, 2012 [8]

Dengue disease pathological progression is dependent on direct interaction between mosquito-borne virus and the host's receptor molecule(s) [19]. For a better understanding of dengue disease, understanding the molecular mechanisms by which dengue virus binds to its receptor (or receptors) in humans and mosquitoes is essential. In addition, developing effective new dengue therapies requires a thorough understanding of the molecular mechanism (s) of viral entry into host [20]. Binding of dengue virus to its receptor molecules is mediated through a viral envelope glycoprotein, termed E protein [21]. The goal of this chapter is to present a summary of dengue virus receptor molecules proposed as of yet, including their structures, binding properties, and pathological relevance. In mammals, chaperone molecules such as phytosphingolipids (TGL) and sulfated glycosaminoglycans (GAGs) are potentially receptors for carbohydrates [22]. In addition, several lines of evidence suggest that mosquito cells and organs contain a variety of receptor molecules, including GSLs, chaperone-like proteins, lamininbinding proteins, as well as other uncharacterized proteins [23].

\section{MEMBRANE ASSOCIATED PROTEIN (M)}

Membrane associated protein is a membrane glycoprotein works as a part of nucleocapsid and assists to envelop protein to form mature virions. Researchers developed antibodies against prM for Japanese encephalitis virus (JEV), West Nile virus (WNV), and dengue virus [24]. Dengue viruses and West Nile viruses do not react with antibodies against the prM protein of JEV. prM protein can be used to investigate differentiating antibody responses to difference flaviviruses [25]. Infected Aedes albopictus cells were immunoprecipitated for detection of C-prM. Membrane associated protein (M) and non-membrane fragments (pr) were produced by these cells.
In mosquito cells, this cleavage was less efficient. Staphylococcal protein A was subsequently fused to the fragmented proteins. Rabbit antisera were generated from the fusion protein which was stable [26]. A domain of the carboxy terminus of the $\mathrm{E}$ gene is responsible for mediating E-prM interactions in dengue virus, while a peptide in the ectodomain of the E gene mediates cell activity in dengue virus [27].

\section{ENVELOPE PROTEIN (E)}

Envelop protein present on the surface of the viruses is extremely involved in virus attachment with host cell through cell receptors like heparin sulfate DCSIGN. It is most important protein for the entry of virus into cell [28]. This protein has three domains, domain I (structural domain), domain II (dimmers), and domain III (binding domain). Dimmer domain links structural and binding domain [29].

An endosome's reduced $\mathrm{pH}$ sets off a conformational change within viral envelop proteins, which allows dengue virus to enter a host cell [30]. By changing its conformation, the virus is able to merge with the host cell membrane [31]. The way that flaviviruses fuse using the E protein's distal barrels is by inserting them into the cell membrane [32]. In the crystal structure of E's soluble ectodermal domain, residues that influence $\mathrm{pH}$ for fusion is surrounded by a hydrophobic pocket [33]. These hydrophobic pockets formed at the junction of two domains open and close at the $\beta$ hair pins. Thus, it can be used in testing antiviral compounds [34].

\section{HEPARAN SULFATE}

The highly acidic linear polysaccharide heparan sulfate (HS) has a very variable structure. All mammalian tissues and cell surfaces express it, along with the extracellular matrix and basement membrane. 
By interacting with diverse polypeptides and exerting diverse functions, HS is synthesized to attach to various core proteins to form HS-proteoglycans [35]. Heparan sulfate (HS) is a glycosaminoglycan (GAG) that is ubiquitously present on cell surfaces, in the extracellular matrix (ECM), and in the basement membrane (BM).

Hexuronic acid and d-glucosamine are repeated disaccharides in each HS molecule [36]. These units are said to exhibit immense structural diversity due to substitutions with sulfate groups [37] (Fig. 1). Mast cells only contain HS which is highly sulfated and structurally related to heparin but not to HS. ER, Golgi apparatus, and trans Golgi network play key roles in HS chain biosynthesis and modification, which ultimately results in HS-proteoglycans (HSPG) that are attached to protein cores (Fig. 1) [38].

In addition to endoglycosidase and heparanase [39], HS chains can be modified by Sulf1 and Sulf2 "endosulfatases."

HS chains are not essential for the function of core proteins [40], HS predominantly dictates the ligand-binding capability and therefore the biological roles of HSPG. Moreover, despite the fact that different cell types express similar core proteins, the HS chains these core proteins carry have markedly different functions, such that HSPG is widely distributed within mammalian physiology and has a variety of roles [19].

By binding to cytokines, chemokines, growth factors, and morphogens at the cell surface, HSPG prevent their degradation, thereby creating gradients of temporary stores of morphogens essential for development [41]. Besides acting as endocytosis receptors, these proteins also act as lysosomal degradation receptors, which ensure nutrient delivery to the cell. In addition, they participate in the endocytosis of cellular receptors [42]. Chemokines are transported across endothelial cells by these proteins. In addition, they act as coreceptors of fibroblast growth factor (FGF) and FGF receptor, either in trans (if expressed on different cells) or cis (if expressed on the same cells). On proteolytic breakdown of syndecans, they act as intracellular signal transducers. They have an important role in development and in maintaining stem cell niches [43]. Angiogenesis, blood coagulation, development, and cell homeostasis are among the many activities they mediate $[R]$. Pathogens, particularly viruses, use highly sulfated HSPG to attach to cell surfaces [44].

\section{HEPARAN SULFATE PROTEOGLYCANS AS VIRAL RECEPTORS}

HSPGs are ubiquitously expressed in most cell types in mammals. The heavily sulfated GAG chains present a global negative charge that can interact electrostatically with the basic residues of viral surface glycoproteins or viral capsid proteins from non-enveloped viruses. Weak interactions enable viruses to concentrate on the cell surface and bind a more specific entry receptor on the cell surface [45].

It has been observed that human endothelial, liver, and animal cell lines interact with the HSPG at various stages of its development [46]. Cell lines from insects (C6/36) may also interact with HSPG. Further, DENV pseudo particles produced with the $\mathrm{E}$ and pre-matrix (prM) proteins of viruses never passing through cells have been shown to bind HSPG and heparin similarly to viruses that have passed through cell lines extensively.

These attachment receptors are first expressed by cell lines expressing HSPG. The wide range of tissues (liver, lymph node, spleen, and bone marrow) infected with DENV may translate to the variety of receptors involved in DENV entry [46].

HSPG was first demonstrated to be binding to DENV in 1997, where HS derived from highly sulfated liver and heparin inhibited DENV2 [47].

HS chains have been shown to serve as attachment factors for a variety of microorganisms and viruses, including flaviviruses [48]. In multiple studies, HS has been shown to play a role in the DV infection process [24], suggesting that HS may indeed serve as a receptor or co-receptor for DV infection of host cells. Other studies investigating the role of HS in DV infection have demonstrated that DV, when propagated under certain conditions in vitro, can undergo adaptive changes resulting in increased affinity for and utilization of HS for cell infection $[49,50]$. Indeed, similar studies with other flaviviruses, including TBEV and $\mathrm{JEV}$, have also shown the potential of these viruses to undergo genetic changes on cell culture propagation which also confer an increased HS binding phenotype [51].

Studies done by Acharya et al. (2015) stated that DV strains showed an enhanced binding to HS after repeatedly passaging in cell lines [52]. Artpradit utilized a new technology named recombinant subviral particles (RSPs) to screen for the possible role of HS in the DV entry into the host cells.

Unlike heparin and HS, RSPs are designed in a way that allows them to interact with Vero cells in a similar manner. They used all the four strains of DV1 to produce RSPs with their native prM-gpE sequences. Identity of the RSPs were examined using Western blot, MALDI-MS, and sucrose gradient ultracentrifugation. Furthermore, a substantial number of studies have confirmed the positive interaction between HS and DV by ELISA and chromatography using immobilized heparin [53]. Studies done by Bhatt et al., 2021, also stated that rate of infection was also altered on treating the cells with heparinases [1] or soluble heparin/HS [54]. HC and soluble heparin inhibited all four strains of RSP, as well as infected the DV isolates Studies by Artpradit showed all four strains of RSP had symptoms of infection and inhibition by HC and HS. These findings collectively prove of the possible interaction between DV and HS.

Interestingly, though all RSPs were found to be bound to heparin in ELISA studies, the intensity of binding varied across RSP concentrations between strains. Strains with low-passage histories showed more affinity to heparin than those with high passage strains. ELISA binding results also confirmed of a greater interaction between heparin and the two RSPs of low-passage strains. High competition rates were found between high-passage strain RSPs and low-passage strain RSPs. Low passage strains also had relatively higher $\mathrm{IC}_{50}$ values for both heparin and HS competition, which states that these RSPs bound more strongly to immobilized heparin. These results support the conclusion that both low-passage and high-passage strains of DV1 utilize HS as an attachment factor [54].

Unlike heparin, HS has a different level of sulfation, which was responsible for competing for RSP binding to immobilized heparin and inhibiting RSP binding to Vero cells. While other studies have found HS as necessary for DV binding and infection [55], a few studies have shown that heparin and highly sulfated HS, but not unmodified HS, are able to bind DV/gpE and/or inhibit infection [56]. In addition to the various strains and serotypes, different assay formats were also utilized with our study, which may lead to different observations.

Several flaviviruses, including DV2 and DV4, have been shown to undergo adaptive changes leading to an enhanced HS-binding phenotype when propagated under specific cell culture conditions [57]. Even reports from the previous investigations of DV1 confirm that HS is a necessary attachment factor for DV1 [57]. Additional viral and biochemical studies are needed to elucidate the mechanisms of HS usage by different strains and serotypes of DV [58]. A number of HS-mimicking molecules with anti-DV activity such as fucoidan, carageenan, DL-galactan, and $\alpha$-dglucans [59] and PI-88 are shown to increase survival in a mouse model of DV infection [60].

The previous reports stated that there are two conserved regions within the envelope protein primary structure which could bind to the heparin. On careful examination of the envelope protein 


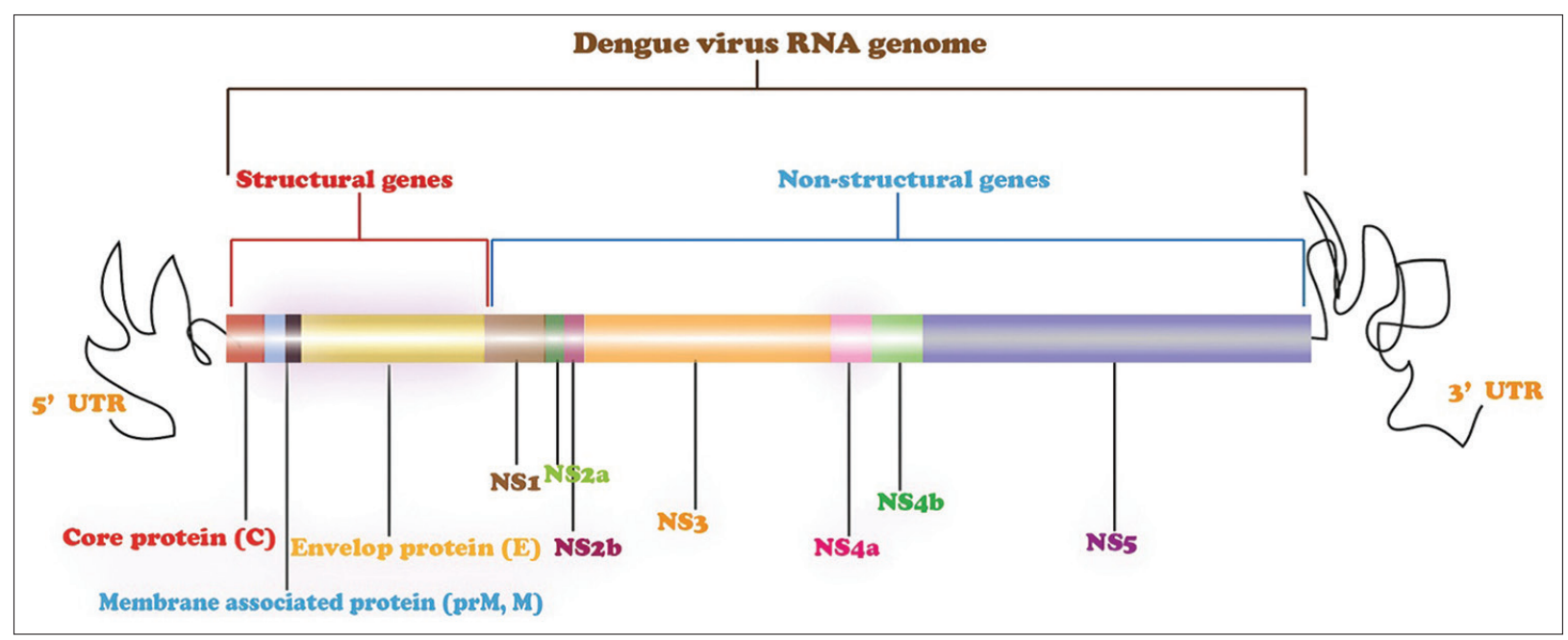

Fig. 3: Dengue virus genome. Dengue virus genome encodes 10 viral proteins including 3 structural proteins (C, M, and E) responsible for viral structure and viral attachment to host cell and seven non-structural proteins (NS1, NS2A, NS2B, NS3, NS4A, NS4B, and NS5) that are involved in viral replication and other cellular function

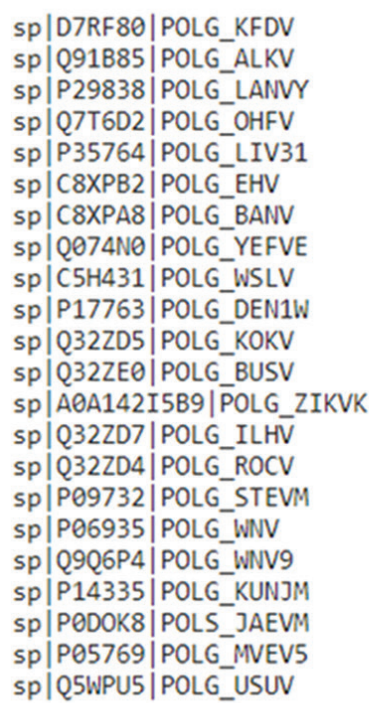

\begin{tabular}{|c|c|c|}
\hline CLAPTYATRCTHLQ & & \\
\hline CIAPTYATRCTHI & & SGIQGTTRVSLVLELGGCVTLTAEGKPSVDWLDDIHQENP \\
\hline & & \\
\hline & & \\
\hline & & QGTTRVTLVLELGGCVTITAEGKPSVDW \\
\hline & & \\
\hline & & QGVQGTTWVNLVLEQGGCVTIMAEGKPSVDWMDNIKFTSP \\
\hline & & EVHGGTWVSATLEQGKCVTVMAPDKPSLDISLQTVAIDGP \\
\hline ris & RDF & RGLDGNTWVSWVLEOGSCVTLIADNKPSVD \\
\hline MAMR QVIG & RDF & EGLSGATWVDWLEHGSC/TTMAKDKPTLDIELLKTEVTNP \\
\hline YYSIR & & EVSGG TWVVVLERGGCVTIMAPDKPTIDLELTSTIAKSM \\
\hline LVAP & & EGLSGGTWVDWLEHGGCVTVRVEGKPTLDFELVQTKATGL \\
\hline LIAF & & EGMSGGTWVDWLEHGGCVTVMAQDKPTVDIELVTTTVSNM \\
\hline & & EGLSGGTWVDIVLEGGSCVTVMAKDKPTLDIKLIRMEAKDL \\
\hline & & EGMSGGTWVDIVLEGDGCVTIMAKDKPTLDIRLLKMEAKDL \\
\hline LIAPAYSFNCLGTS & & EGASGATWIDLVLEGGSCVTVMAPEKPTLDFKVMKMEATEL \\
\hline & & EGVSGATWVDLVLEGDSCVTIMSKDKPTIDVKMMNMEAANL \\
\hline & & EGVSGATWVDLVLEGDSCVTIMSKDKPTIDVKMMNMEAANL \\
\hline LVAPAYSFNCLGN & & EGVSGATWVDLVLEGDSCVTIMSKDKPTIDVKMMNMEAANL \\
\hline & & \\
\hline & & \\
\hline LVAPAYSFNCLGM & & EGVSGATWVDWLEGDSCITIMAKDKPTIDIKMMETEATNL \\
\hline & & ${ }^{*} \quad * *: \quad *^{*}: .{ }^{*}: *$ \\
\hline
\end{tabular}

CLAPTYATRCTHLQ RDFV SGTQGTTRVSLVLELGGCVTLTAEGKPSVDVWLDDIHQENP CLAPTYATRCTHLQ RDFV SGIQGTTRVSLVLELGGCVTLTAEGKPSVDWLDDIHQENP ALVPAYASRCTHLE RDFV TGVQGTTRLTLVLELGGCVTVTADGKPSLDWLDSIYQESP CLAPAYASRCTHLE IRDFY TGTQGTTRVTLVLELGGCVTITAEGKPSMDWLDSIYQENP AIGPAYSTHCVGIP RDFV GVQNTWVIVLDGSCVTISSDNKPSVDIWLDSIFISSP ALGPAYATHCVGIP RDFV QGVQGTTWVNLVLEQGGCVTIMAEGKPSVDWMDNIKFTSP

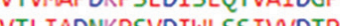
LVTPSMAMRQVGIG RDFV ELSGATWVDWLEHGSCTTMAKDKPTLDIELLKTEVTNP TIMAPDKPTIDLELTSTIAKSM LIAPAYSIRCIGVS IRDFVEGMSGGTWVDWLEHGGCVTVMAQDKPTVDIELVTTTVSNM LIAPAYSLNCLGIS RDFFE ELSGGTWVDIVLEGGSCVTVMAKDKPTLDIKLIRMEAKDL LIAPAYSINCLGVT RDFVEGMSGGTWVDIVLEGDGCVTIMAKDKPTLDIRLLKMEAKDL LVAPAYSFCLG RDF LVAPAYSFNCLGMS RRDFLEGVSGATWVDLVLEGDSCVTIMSKDKPTIDVKMMNMEAANL LAPAYSFNCLGMS RDF EGSGATWDLVLECDSCVTI LVAPAYSFNCLGMS RDFI EGASGATWVDLVLEGDSCITIMAADKPTLDIRMMNIEATNL .* $\quad * * *: * * *:$ : * : . *:* **: :*. :

Fig. 4: Multiple sequence alignment of the envelope protein sequences of various viral strains along with dengue virus. Detailed representation of black box sequence (horizontal) for myriad proteins [VGIGNRDFVEGLSGATWVDVVLEHGSC] which binds HS. Vertical box denotes the conserved domain in all the viral strains

sequence of the dengue 2 virus, two such putative GAG-binding motifs were screened one between 284 and 310 and other between 386 and 411 [60]. P17763 (Dengue virus); A0A142I5B9 (Zika virus); P0DOK8 (Japanese encephalitis virus, Strain 38); P06935 (West Nile virus); Q32ZE0 (Bussuquara virus); Q32ZD5 (Kokobera virus); Q32ZD7 (Ilheus virus, ILHV); P05769 (Murray valley encephalitis virus); P14335 (Kunjin virus); P09732 (St. louis encephalitis virus); Q5WPU5 (Usutu virus); Q32ZD4 Rocio virus, ROCV); Q074N0 (Yellow fever virus); С8XРB2 (Edge Hill virus); C8XPA8 Banzi virus, BANV); C5H431 Wesselsbron virus; D7RF80 (Kyasanur forest); Q91B85 (Alkhumra hemorrhage virus); P29838 (Langat virus); Q7T6D2 (Omsk hemorrhagic virus); and P35764 (Louping ill virus). About 29 strains of viruses were screened for their conserved domains within the envelope protein.
Within the polyprotein of DENV, 115-280 regions holds Protein prM, 115-205 region holds Peptide pr, 206-280 holds Small envelope protein M and 281-775 holds Envelope protein E. Researchers found the two regions responsible for binding to HS $[58,61]$ to be 284 and 310 [VGIGNRDFVEGLSGATWVDVVLEHGSC] and other between 386 and 411 [GLFGKGSLITCAKFKCVTKLEGKIVQY]. Clustal omega was used for the multiple sequence alignment to screen for the conserved domains within the envelope protein regions of all of the above 2 viral strains including DENV [P17763].

The multiple sequence alignment results (Figs. 3-5) clearly starts that the putative sequence exists among other viral strains also, and the conserved domains are found to be within the regions binding to the HS. This confirms of the role of interaction between the envelope protein domains with the HS chains. 


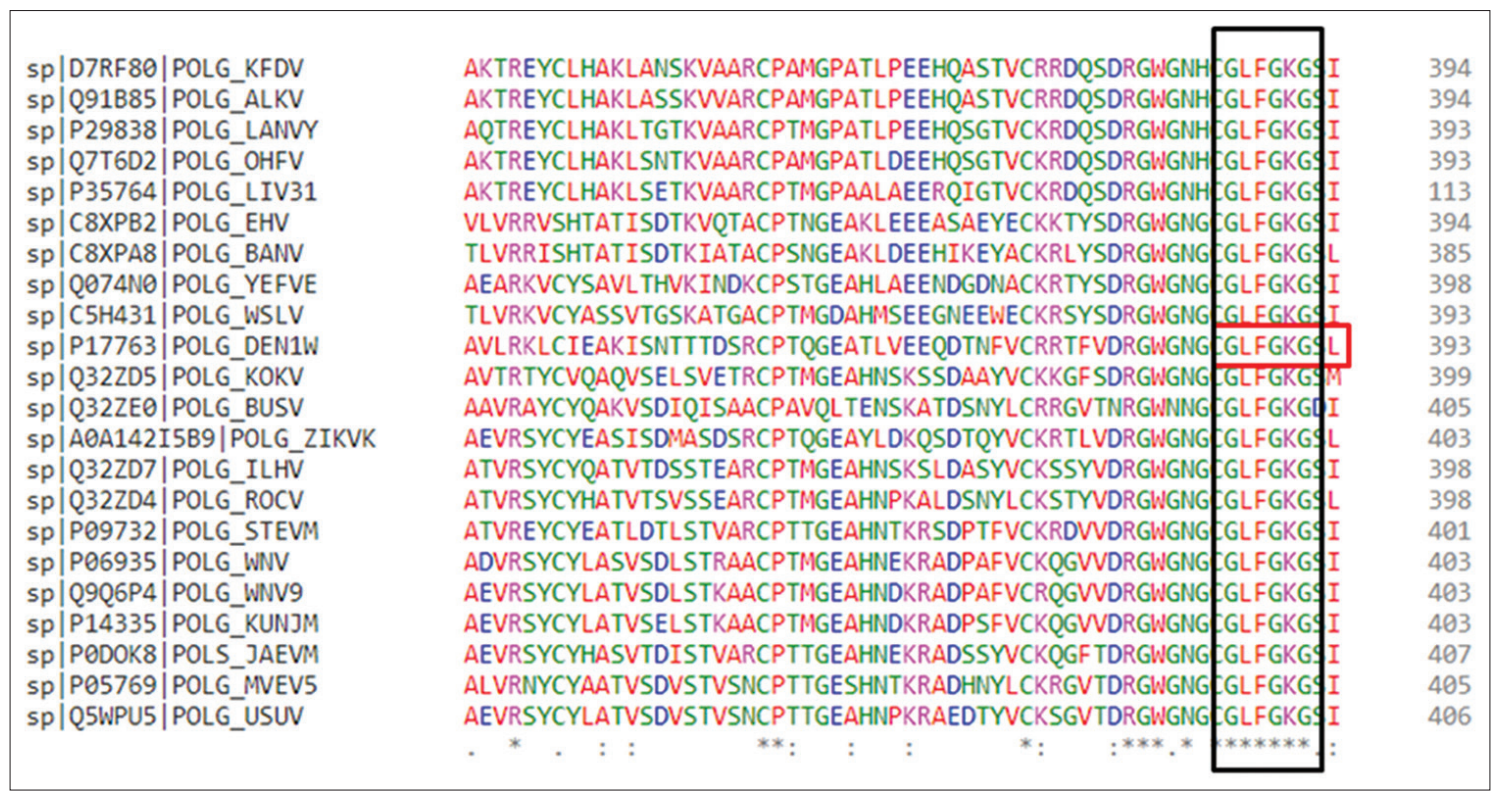

Fig. 5: Multiple sequence alignment of the envelope protein sequences of various viral strains along with dengue virus. An example of a putative sequence is highlighted in red box (horizontal) between 386 and 411 [GLFGKGSLITCAKFKCVTKLEGKIVQY] which is said to bind to HS. Vertical box denotes the conserved domain in all the viral strains

\section{CONCLUSION}

We provide schematic and systematic evidence supporting an interaction between HS and envelope protein of DENV. Many studies concluded that the envelope protein binds to HS to gain entry into the host cells. Similarly, it was determined that HS could also serve as a landing site for clinically relevant DV1 strains. Other different evidencebased approaches need to be studied to for similar interactions. The reports available so far, states that HS and envelope protein interact positively in a cooperative manner for effective entry into the host cells.

\section{REFERENCES}

1. Gabriel M, Navarro GS, de Borba L, Rossi AH, Gamarnik AV, Estrada LC. Dengue virus capsid protein dynamics reveals spatially heterogeneous motion in live-infected-cells. Sci Rep 2020;10:8751.

2. Iglesias NG, Mondotte JA, Byk LA, de Maio FA, Samsa MM, Alvarez C, et al. Dengue virus uses a non-canonical function of the host GBF1-Arf-COPI system for capsid protein accumulation on lipid droplets. Traffic 2015;16:962-77.

3. Biswas P, Ganguly S, Debnath B. Dengue fever: Stages, complication, diagnosis, and prevention strategies. Asian J Pharm Clin Res 2021;14:3-11.

4. Chen WB, Maguire T. Nucleotide sequence of the envelope glycoprotein gene of a dengue- 2 virus isolated during an epidemic of benign dengue fever in Tonga in 1974. Nucleic Acids Res 1990;18:5889.

5. Malacrida L, Hedde PN, Ranjit S, Cardarelli F, Gratton E. Visualization of barriers and obstacles to molecular diffusion in live cells by spatial pair-cross-correlation in two dimensions. Biomed Opt Express 2017;9:303-21.

6. Acharya D, Paul AM, Anderson JF, Huang F, Bai F. Loss of glycosaminoglycan receptor binding after mosquito cell passage reduces chikungunya virus infectivity. PLoS Negl Trop Dis 2015;9:e0004139.

7. Bacia K, Haustein E, Schwille P. Fluorescence correlation spectroscopy: Principles and applications. Cold Spring Harb Protoc 2014;2014:709-25.

8. Acosta EG, Piccini LE, Talarico LB, Castilla V, Damonte EB. Changes in antiviral susceptibility to entry inhibitors and endocytic uptake of dengue-2 virus serially passaged in vero or C6/36 cells. Virus Res 2014;184:39-43.

9. Shepard DS, Undurraga EA, Halasa YA, Stanaway JD. The global economic burden of dengue: A systematic analysis. Lancet Infect Dis 2016;16:935-41

10. Medagama A, Dalugama C, Meiyalakan G, Lakmali D. Risk factors associated with fatal dengue hemorrhagic fever in adults: A case control study. Can J Infect Dis Med Microbiol 2020;2020:1042976.

11. Kalyani G, Thanushree N. The dengue vaccines: Assessment of future prospects, treatment, and vaccine challenges. Asian J Pharm Clin Res 2020;13:4-9.

12. Cojandaraj L, Para HS, Tsepal T, Kumari S. Dengue predominance in India: A report. Asian J Pharm Clin Res 2020;13:5-9.

13. He Y, Wang M, Chen S, Cheng A. The role of capsid in the flaviviral life cycle and perspectives for vaccine development. Vaccine 2020;38:6872-81.

14. Bhatt S, Gething PW, Brady OJ, Messina JP, Farlow AW, Moyes CL. The global distribution and burden of dengue. Nature 2013;496:504-7.

15. Bhatt P, Sabeena S P and Varma M. Current understanding of the pathogenesis of dengue virus infection. Curr Microbiol 2021;78:17-32.

16. Morando MA, Barbosa GM, Cruz-Oliveira C, da Poian AT, Almeida FC. Dynamics of Zika virus capsid protein in solution: The properties and exposure of the hydrophobic cleft are controlled by the alpha-helix 1 sequence. Biochemistry 2019;58:2488-98.

17. Cagno V, Andreozzi P, D’Alicarnasso M, Silva PJ, Mueller M, Galloux M, et al. Broad-spectrum non-toxic antiviral nanoparticles with a virucidal inhibition mechanism. Nat Mater 2018;17:195-203.

18. Cagno V, Tseligka ED, Jones ST, Tapparel C. Heparan sulfate proteoglycans and viral attachment: True receptors or adaptation bias? Viruses 2019;11:596

19. Samsa MM, Mondotte JA, Iglesias NG, Assuncao-Miranda I, BarbosaLima G, da Poian AT. Dengue virus capsid protein usurps lipid droplets for viral particle formation. PLoS Pathog 2009;5:e1000632.

20. Tan TY, Fibriansah G, Lok SM. Capsid protein is central to the birth of flavivirus particles. PLoS Pathog 2020;16:e1008542.

21. Cheng CC, Sofiyatun E, Chen WJ, Wang LC. Life as a vector of dengue virus: The antioxidant strategy of mosquito cells to survive viral infection. Antioxidants (Basel) 2021:10:395.

22. Kostyuchenko VA, Zhang Q, Tan JL, Ng TS, Lok SM. Immature and mature dengue serotype 1 virus structures provide insight into the maturation process. J Virol 2013;13:7700-7.

23. Chong ZL, Sekaran SD, Soe HJ. Diagnostic accuracy and utility of three dengue diagnostic tests for the diagnosis of acute dengue infection in Malaysia. BMC Infect Dis 2020;20:210.

24. Byk LA, Gamarnik AV. Properties and functions of the dengue virus capsid protein. Annu Rev Virol 2016;3:263-81.

25. Cruz-Oliveira C, Freire JM, Conceição TM, Higa LM, Castanho MA, da Poian AT. Receptors and routes of dengue virus entry into the host cells. FEMS Microbiol Rev 2015;39:155-70.

26. Dey D, Poudyal S, Rehman A, Hasan SS. Structural and biochemical insights into flavivirus proteins. Virus Res 2021;296:198343.

27. Utomo DIS, Pambudi S, Sjatha F, Kato T, Park EY. Production of dengue virus-like particles serotype-3 in silkworm larvae and their ability to elicit a humoral immune response in mice. AMB Express 2020;10:147.

28. Scaturro P, Trist IM, Paul D, Kumar A, Acosta EG, Byrd CM, et al. 
Characterization of the mode of action of a potent dengue virus capsid inhibitor. J Virol 2014;88:11540-55.

29. Fahimi H, Mohammadipour M, Kashani HH, Parvini F, Sadeghizadeh M. Dengue viruses and promising envelope protein domain III-based vaccines. Appl Microbiol Biotechnol 2018;102:2977-96.

30. Martins IC, Gomes-Neto F, Faustino AF, Carvalho FA, Carneiro FA, Bozza PT, et al. The disordered N-terminal region of dengue virus capsid protein contains a lipid-droplet-binding motif. Biochem J 2012;444:405-15.

31. Fahimi H, Mohammadipour M, Haddad Kashani H. Dengue viruses and promising envelope protein domain III-based vaccines. Appl Microbiol Biotechnol 2018;102:2977-96.

32. Flores EB, Bartee MY, Bartee E. Reduced cellular binding affinity has profoundly different impacts on the spread of distinct poxviruses. PLoS One 2020;15:e0231977.

33. Yong XE, Palur VR, Anand GS, Wohland T, Sharma KK. Dengue virus 2 capsid protein chaperones the strand displacement of 5'-3' cyclization sequences. Nucleic Acids Res 2021;49:5832-44.

34. Gopal S. Syndecans in inflammation at a glance. Front Immunol 2020;11:227.

35. Guzman MG, Alvarez M, Halstead SB. Secondary infection as a risk factor for dengue hemorrhagic fever/dengue shock syndrome: An historical perspective and role of antibody-dependent enhancement of infection. Arch Virol 2013;158:1445-59.

36. Kumar R, Singh N, Abdin MZ, Patel AH, Medigeshi GR. Dengue virus capsid interacts with DDX3X-a potential mechanism for suppression of antiviral functions in dengue infection. Front Cell Infect Microbiol 2018;7:542.

37. Hao C, Xu H, Yu L, Zhang L. Heparin: An essential drug for modern medicine. Prog Mol Biol Transl Sci 2019;163:1-19.

38. Hidari KI, Suzuki T. Dengue virus receptor. Trop Med Health 2011;39:37-43.

39. Idrees S, Ashfaq UA. A brief review on dengue molecular virology, diagnosis, treatment and prevalence in Pakistan. Genet Vaccines Ther 2012;10:6.

40. Hidari KI, Suzuki T. Dengue virus receptor. Trop Med Health 2011;39 Suppl 4:37-43.

41. Lim MQ, Kumaran EA, Tan HC, Lye DC, Leo YS, Ooi EE, et al. Crossreactivity and anti-viral function of dengue capsid and NS3-specific memory T cells toward zika virus. Front Immunol 2018;9:2225.

42. Kobayashi K, Mizuta K, Koike S. Heparan sulfate attachment receptor is a major selection factor for attenuated enterovirus 71 mutants during cell culture adaptation. PLoS Pathog 2020;16:e1008428.

43. Kreuger J, Kjellén L. Heparan sulfate biosynthesis: Regulation and variability. J Histochem Cytochem 2012;60:898-907.

44. Ladner JT, Wiley MR, Prieto K, Yasuda CY, Nagle E, Kasper MR, et al. Complete genome sequences of five Zika virus isolates. Genome Announc 2016;4:e00377-16.
45. Liu T, Zhang L, Joo D, Sun SC. NF- $\kappa B$ signaling in inflammation. Signal Transduct Target Ther 2017;2:17023.

46. Modhiran N, Watterson D, Muller DA, Panetta AK, Sester DP, Liu L, et al. Dengue virus NS1 protein activates cells via Toll-like receptor 4 and disrupts endothelial cell monolayer integrity. Sci Transl Med 2015;7:304ra142.

47. Okumura M, Matsuura-Miura M, Makino R. Enhancement of guinea pig cytomegalovirus infection by two endogenously expressed components of the pentameric glycoprotein complex in epithelial cells. Sci Rep 2020;10:8530.

48. Pierson TC, Diamond MS. The continued threat of emerging flaviviruses. Nat Microbiol 2020;5:796-812.

49. Saeed AF, Wang R, Ling S, Wang S. Antibody engineering for pursuing a healthier future. Front Microbiol 2017;8:495.

50. Sharma A, Vasanthapuram RM, Venkataswamy M. Prohibitin 1/2 mediates dengue-3 entry into human neuroblastoma (SH-SY5Y) and microglia (CHME-3) cells. J Biomed Sci 2020;27:55.

51. Shi D, Sheng A, Chi L. Glycosaminoglycan-protein interactions and their roles in human disease. Front Mol Biosci 2021;8:639666.

52. Shukla R, Ramasamy V, Shanmugam RK, Ahuja R, Khanna N. Antibody-dependent enhancement: A challenge for developing a safe dengue vaccine. Front Cell Infect Microbiol 2020;10:572681.

53. Davis DA, Parish CR. Heparan sulfate: A ubiquitous glycosaminoglycan with multiple roles in immunity. Front Immunol 2013;4:470.

54. St John AL, Rathore APS. Adaptive immune responses to primary and secondary dengue virus infections. Nat Rev Immunol 2019;19:218-30.

55. Tang TC, Alonso S, Ng LP. Increased serum hyaluronic acid and heparan sulfate in dengue fever: Association with plasma leakage and disease severity. Sci Rep 2017;7:46191

56. Rivino L, Kumaran EA, Jovanovic V, Nadua K, Teo EW, Pang SW, et al. Differential targeting of viral components by CD4+ versus CD8+ $\mathrm{T}$ lymphocytes in dengue virus infection. J Virol 2013;87:2693-706.

57. Annaval T, Wild R, Crétinon Y, Sadir R, Vivès RR, Lortat-Jacob H. Heparan sulfate proteoglycans biosynthesis and post synthesis mechanisms combine few enzymes and few core proteins to generate extensive structural and functional diversity. Molecules 2020;25:4215.

58. Castilla V, Piccini LE, Damonte EB. Dengue virus entry and trafficking: Perspectives as antiviral target for prevention and therapy. Future Virol 2015;10:625-45.

59. Mii Y, Takada S. Heparan sulfate proteoglycan clustering in wnt signaling and dispersal. Front Cell Dev Biol 2020;8:631.

60. Schuurs ZP, Hammond E, Elli S, Rudd TR, Mycroft-West CJ, Lima MA, et al. Evidence of a putative glycosaminoglycan binding site on the glycosylated SARS-CoV-2 spike protein N-terminal domain. Comput Struct Biotechnol J 2021;19:2806-18.

61. Lia RA, Lutfan L, Yien LH, Asa H, Kusnanto H, Rocklöv J. Prediction of dengue outbreaks based on disease surveillance and meteorological data. PLoS One 2016;11:1-18. 